\title{
Sampling Interval Selection for 3D Surface Roughness Measurements Using the Contact Method
}

\author{
Wojciech Marek Żyłka ${ }^{1,2}$ \\ 1 College of Natural Sciences, University of Rzeszow, aleja Tadeusza Rejtana 16C, 35-310 Rzeszów, Poland \\ 2 Department of Electronics, Telecommunications \& Mechatronics, Polytechnic Faculty, University of Applied \\ Sciences, Mickiewicza 8, 33-100 Tarnów, Poland \\ e-mail:wzylka@urz.edu.pl
}

\begin{abstract}
The article presents the impact of sampling interval $\Delta \mathrm{X}=\Delta \mathrm{Y}$ upon the precision of parametrical assessment of roughness of selected surfaces. Moreover this study introduces theoretical analysis of sampling interval selection based on analysis of the probability of covering an unordered set of extreme points of surface with an ordered set of measurement points. As the result, the final formula was formulated, which enables to calculate the maximum sampling rate $\Delta X=\Delta Y$. This guarantees a full $100 \%$ coverage of the vertices examined by the unevenness of the measuring grid.
\end{abstract}

Keywords: surface texture, sampling interval, measuring grid, measuring stylus.

\section{INTRODUCTION}

In recent years, very dynamic development of measurement technology has been observed. As a result of the constant competition in the market, new machines, devices, new technologies and solutions appear in a relatively short period of time. At the same time, new possibilities for surface analysis in 3D with nanometer accuracy have appeared [14]. Computer assistance has simplified the analysis of measurement results, including the identification of the characteristic functions of the geometric surface structure - autocorrelation, load capacity, power spectral density and others [7]. In 3D measurements, the sampling interval has become very important. In the case of surface analysis in $3 \mathrm{D}$, it defines the frequency limits (wavelength) of the measurement and has a significant effect on the parametric evaluation of the surface geometry. Nowadays, selection of the sampling interval is based on arbitrary norms and recommendations, generally without adequate justification [7]. Increasing the sampling interval along with decreasing time and cost leads to an increase of the value of the parameters interval and a decrease in the inclination of the profile and the curvature of the vertices, especially of the random profiles. A step which is not big enough leads to redundancy and excessive correlation of ordinates [12]. In order to reduce the time and cost of researches, it is necessary to determine the maximum sampling rate that guarantees the actual depiction of the area to be measured.

Heretofore, no procedure has been devised to select the sampling interval for surface stereometry hence numerous publications in this field are still appearing. What is interesting is the fact that in almost each of these studies another suggestion appears. Practically, there are as many $\Delta X=\Delta Y$ values as studies. The aim of research made in the present paper follows from the emergence of many suggestions as to the method of selecting the sampling interval.

In many scientific articles, the issue of accurate surface mapping and determining the exact values of parameters describing its 
topography are discussed. The research concerns contact and contactless measurement techniques [16]. Rutherford [8] tested backscattering spectroscopy spectra and their relationship to surface roughness. The shape of the RBS spectra has been found to change strongly with increasing sample roughness and an increasing angle of the incoming ion beam. In [9] there was presented a sampling method to measure surface roughness of circular flat. This non-contact method can effectively use the surface roughness of sampling points to estimate the surface roughness of the overall optical surface. On the other hand, paper [3] presents a data sampling technique for the inspection of waving surfaces. Authors in [15] describe intelligent sampling strategy for surface measurement. A multi-sensor data fusion algorithm was developed based on dependant Gaussian processes regression model and is served as the mathematical foundation to perform adaptive sampling of the surfaces with Bayesian inference by taking the bias and the variance of the fused model as the sampling criteria. In [2] the author proposes a new method for surface measurements combining space-filling scan paths and adaptive sampling. Sampling positions are intelligently suggested along the scan Path and the data amount can be reduced to approximately $3-4 \%$. Numerous articles are concerned with research of sampling methods in surface measuring [1, 4-6, 10-11, 13]. New measurement strategies are being studied, which reduces the measurement time and increases the accuracy of surface mapping.

In this paper $[17,19]$, choosing the sampling interval was guided by the principle that $\Delta \mathrm{X}, \Delta \mathrm{Y}$ was half the radius of the rounded measuring needle and shorter than the applied filter. So for example, authors of works [12, 18, 20,28] mention in their studies, that the minimum sampling interval depends on the size of measuring needle, it should be close to half of its radius of roundness.

In most digital profilometers, especially portable (workshop) ones, the sampling interval results from the assumed length of the measurement segment and its division into a specific number of points. For example, in the TALYPROFIL software from Rank Taylor Hobson, which is compatible with their profilometers, the number of profile points may not exceed 8192 and, depending on the adopted section, the sampling interval is $0.5 \mu \mathrm{m}, 1 \mu \mathrm{m}$ or $2 \mu \mathrm{m}$. However, regardless of the adopted measuring section, the interval cannot be smaller than $0.5 \mu \mathrm{m}$. In this solution, it is difficult to assess the influence of the sampling interval on the values of surface roughness parameters, because they also depend on the length of the measuring segment, which in this case is also variable [39].

For example, the paper [40] (Table 1) reviews the literature on sampling interval and depends $\Delta \mathrm{X}, \Delta \mathrm{Y}$ on the value of the rounding radius of the measuring stylus $\rho$ and $\Delta \mathrm{X}, \Delta \mathrm{Y}$. According to the author, $\rho$ and $\Delta \mathrm{X}, \Delta \mathrm{Y}$ are two parameters that greatly affect the measurement result.

Yet another way to determine the sampling interval is to relate it to the cutoff wavelength. Its value should be $1 / 100$ of the filter cutoff wavelength or the ratio of filter cutoff wavelengths $\lambda_{C} / \lambda_{S}$ should be 300 [41]. J. Michalski has done an extensive literature review on the sampling interval. The author found that for periodic profiles, the correct value of the sampling interval determined from the autocorrelation function is $0.4 \cdot D K_{0.1}\left(D K_{0.1}\right.$ - is the correlation length at an autocorrelation function value of 0.1 ). This corresponds to a sampling interval of $0.4 \beta *(\beta *$ - is the parameter value of the exponential function approximating the autocorrelation function). For a random profile of the drilled surface, the sampling interval is best determined from the relation $1 /\left(4 \cdot f_{k}\right)\left(f_{k}-\right.$ frequency corresponds to the position of the curvature maximum of the function approximating the cumulative normalized spectral power) [42].

With the above listing (Table 2), could be seen how the sampling interval values proposed by many

Table 1. Summary of sampling interval values [40]

\begin{tabular}{|c|c|}
\hline Value $[\mu \mathrm{m}]$ & Literature \\
\hline 1 & {$[19,20]^{1}$} \\
\hline 2 & {$[21,22]^{1}$} \\
\hline 1.4 & {$[23,24]^{1}$} \\
\hline 4 & {$[25]^{1}$} \\
\hline 2 & {$[26,27]^{2}$} \\
\hline$<1.6$ & {$[28]^{2}$} \\
\hline $1 \div 2$ & {$[29]^{3}$} \\
\hline 1.1 & {$[30]^{2}$} \\
\hline 0.63 & {$[12]^{2}$} \\
\hline${ }^{1)}$ Assuming that, rtip $=2 \mu \mathrm{m}$ & \\
\hline $\begin{array}{l}\text { 2) Assuming that, the minimum wavelength calculated } \\
\text { on the basis of the Shannon condition is } 6.3 \mu \mathrm{m}\end{array}$ \\
\hline 3) Assuming that, the profile slope is in the range $15 \div 30^{\circ}$ \\
\hline
\end{tabular}


Table 2. Adopted sampling intervals covering the entire range of their length recommended in the literature [42]

\begin{tabular}{|c|c|c|c|c|c|c|c|c|}
\hline \multirow[b]{2}{*}{ No. } & \multirow{2}{*}{$\begin{array}{l}\text { Sampling interval by } \\
\text { criterion }\end{array}$} & \multicolumn{7}{|c|}{ Surface profile } \\
\hline & & Sinusoidal & Triangular & $\begin{array}{c}\text { Arched } \\
\text { Symmetrical }\end{array}$ & $\begin{array}{l}\text { Arched } \\
\text { veriable }\end{array}$ & $\begin{array}{l}\text { Arched } \\
\text { reverse }\end{array}$ & Drilled & Bored \\
\hline 1. & $1 /\left(2 * f_{0.95}\right),[26]$ & 62 & 62 & 52 & 79 & 74 & 8 & 28 \\
\hline 2. & $1 /\left(2{ }^{*} f_{\mathrm{p}}\right),[31]$ & 51 & 51 & 34 & 52 & 50 & 7 & 14 \\
\hline 3. & $1 /\left(4{ }^{*} f_{\mathrm{K}}\right),[32]$ & 64 & 56 & 38 & 56 & 56 & 7 & 22 \\
\hline 4. & $\begin{array}{c}1 /\left(3^{*} f_{\mathrm{c}}\right) \text { lub } 1 /\left(8^{*}\right. \\
\left.f_{\mathrm{c}}\right),\left(f_{\text {Mmax }}\right),[33]\end{array}$ & $9(240)$ & $9(235)$ & $9(200)$ & $9(235)$ & $9(250)$ & $2(54)$ & $12.5(67)$ \\
\hline 5. & $0.4{ }^{*} \beta,[34]$ & 19 & 17 & 16 & 21 & 21 & 38 & 10 \\
\hline 6. & $2.3{ }^{*} \beta,[35]$ & 108 & 97 & 90 & 120 & 120 & 218 & 57 \\
\hline 7. & $\begin{array}{l}0.4 * D K_{0.1} \\
\left(0.92{ }^{*} \beta\right)\end{array}$ & $19(43)$ & $19(39)$ & $18(36)$ & $24(48)$ & $25(48)$ & $86(86)$ & $10(22)$ \\
\hline 8. & $f_{\mathrm{c}} \sim \lambda_{\mathrm{fall}} / 2.56,[36]$ & 73 & 73 & 73 & 73 & 73 & 7 & 39 \\
\hline 9. & $\rho / 2,[20,22,28]$ & 1.25 & 1.25 & 1.25 & 1.25 & 1.25 & 12.5 & 1.25 \\
\hline 10. & $\rho,[21,22,26,27]$ & 2.5 & 2.5 & 2.5 & 2.5 & 2.5 & 2.5 & 2.5 \\
\hline 11. & $\rho^{*} \sqrt{2},[24]$ & 3.5 & 3.5 & 3.5 & 3.5 & 3.5 & 3.5 & 3.5 \\
\hline 12. & $2{ }^{*} \rho{ }^{*} \sin (\Delta a),[29]$ & 0 & 0.6 & 0 & 0.1 & 0 & 0.1 & 01 \\
\hline 13. & $2 * \rho,[27]$ & 5 & 5 & 5 & 5 & 5 & 5 & 5 \\
\hline 14. & $0.25 * S,[28]$ & 50 & 50 & 50 & 50 & 50 & 3 & 21 \\
\hline 15. & $\lambda_{c} / 100,[21]$ & 8 & 8 & 8 & 8 & 8 & 8 & 8 \\
\hline 16. & $\lambda_{\text {fall }} / 6,[37]$ & 31 & 31 & 31 & 31 & 31 & 3 & 17 \\
\hline 17. & $\lambda_{\text {fall }} / 8,[33]$ & 23 & 23 & 23 & 23 & 23 & 2 & 12.5 \\
\hline 18. & $\lambda_{\text {fali }} / 16,[38]$ & 12 & 12 & 12 & 12 & 12 & 1 & 5.25 \\
\hline 19. & $\lambda_{\text {fali }} / 20,[22]$ & 9 & 9 & 9 & 9 & 9 & 1.0 & 5 \\
\hline
\end{tabular}

researchers vary widely. Their range is practically between values of 0.1 and $120 \mu \mathrm{m}$, even zero.

The guidelines for the operation of threedimensional measuring instruments do not provide any specific recommendations for the selection of measurement parameter values when measuring surfaces with specific geometries in order to obtain reliable SGP mapping results. In such a situation, it seems undoubtedly necessary to carry out analytical and experimental studies to develop a strategy of SGP measurements that guarantee the reliability of SGP mapping and its parametric evaluation.

The purpose of the paper is to develop a scientifically sound method for selecting a sampling interval for obtaining a reliable parametric evaluation of SGP without unnecessarily increasing measurement time and cost. a)

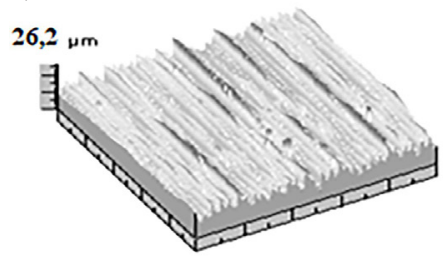

c)

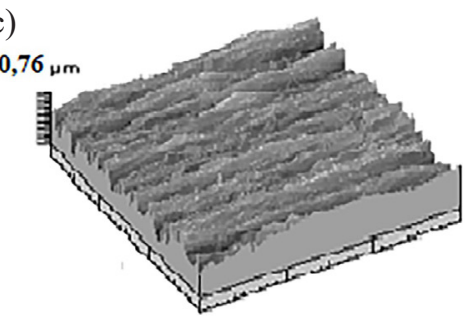

b)

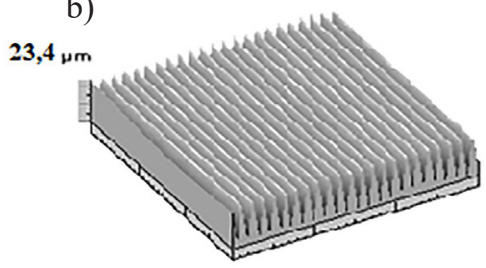

d)

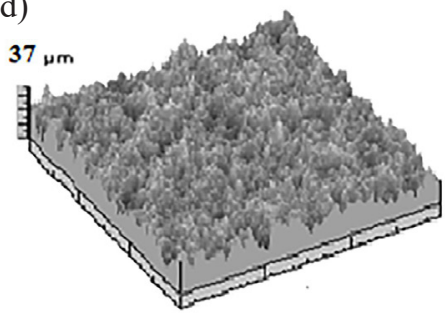

Fig. 1. Tested surfaces: a) anisotropic mixed, b) anisotropic periodic, c) anisotropic random, d) isotropic random 


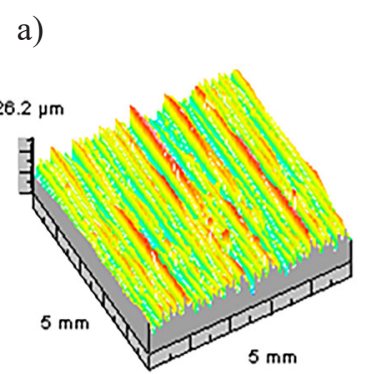

d)

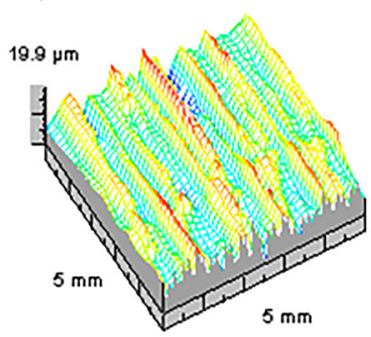

b)
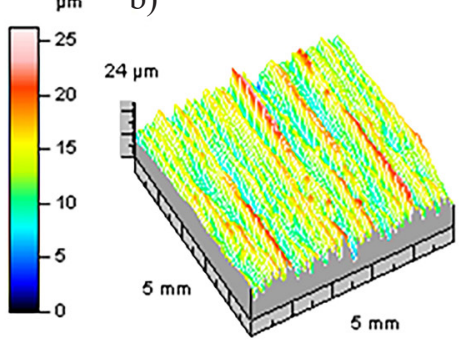

$\mu \mathrm{m} \quad$ e)

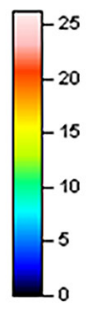

c)

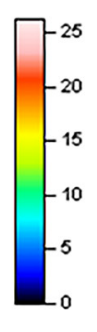

e)

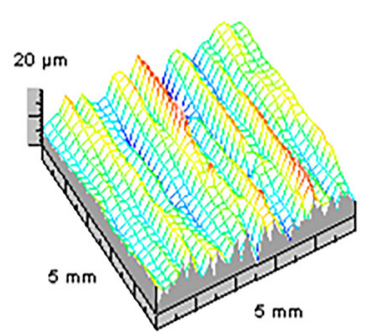

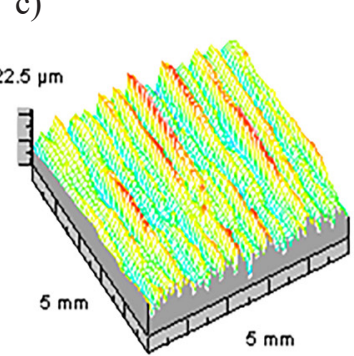

$\mu \mathrm{m}$

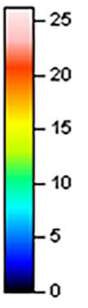

Fig. 2. Roughness measurements on the mixed anisotropic surface with different sampling intervals: a) $\Delta \mathrm{X}=\Delta \mathrm{Y}=5 \mu \mathrm{m}, \mathrm{b}) \Delta \mathrm{X}=\Delta \mathrm{Y}=10 \mu \mathrm{m}$, c) $\Delta \mathrm{X}=\Delta \mathrm{Y}=20 \mu \mathrm{m}$, d) $\Delta \mathrm{X}=\Delta \mathrm{Y}=50 \mu \mathrm{m}, \mathrm{e}) \Delta \mathrm{X}=\Delta \mathrm{Y}=100 \mu \mathrm{m}$
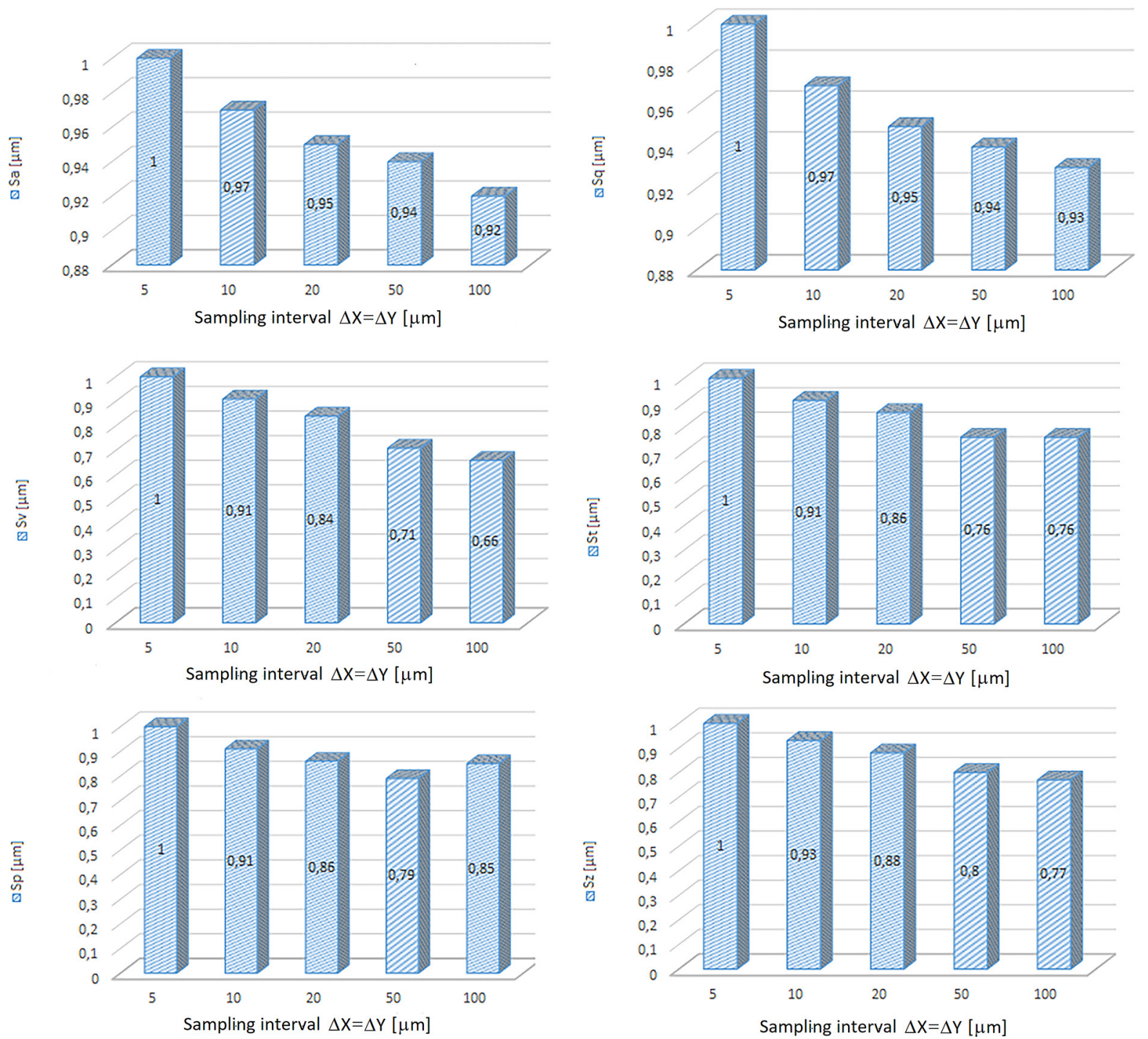

Fig. 3. Change in amplitude parameters values obtained during surface measurement with different sampling intervals relative to $\Delta \mathrm{X}=\Delta \mathrm{Y}=5 \mu \mathrm{m}$ 

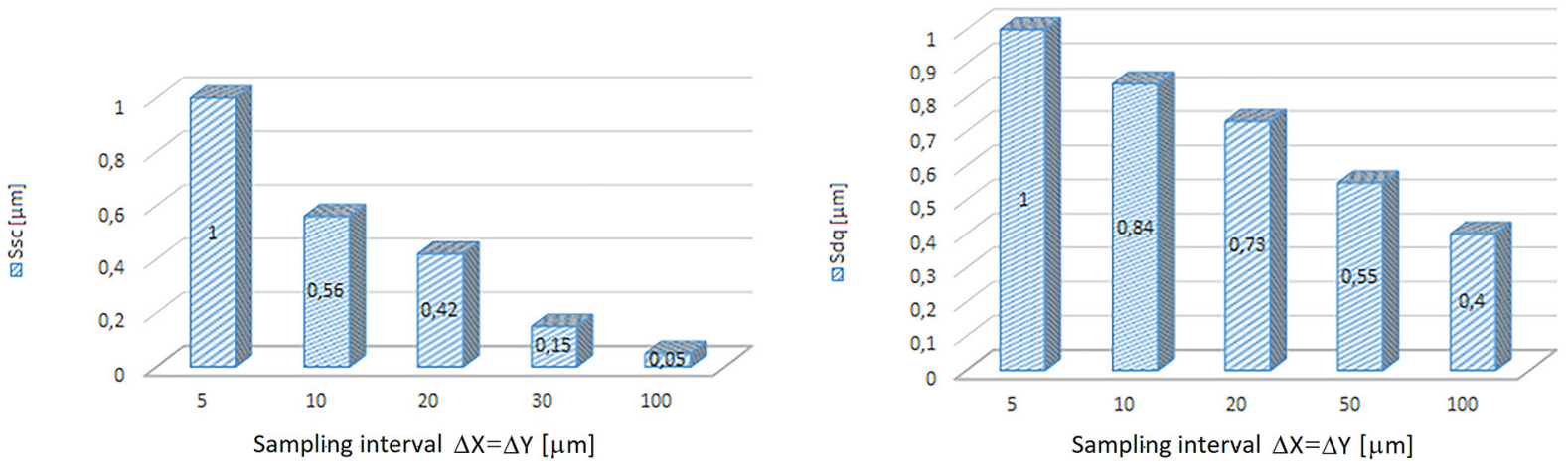

Fig. 4. Change in hybrid parameters values obtained during surface measurement with different sampling intervals relative to $\Delta \mathrm{X}=\Delta \mathrm{Y}=5 \mu \mathrm{m}$

\section{AREA MEASUREMENTS}

Measurements were made using the contact method using a measuring stylus with a rounding radius of $5 \mu \mathrm{m}$ on the following surfaces (Fig. 1): mixed anisotropic, periodic anisotropic - turned surface, random anisotropic - milled surface, random isotropic - peened surface.

In order to obtain reliable results, the same surface area was tested with different sampling lengths with the remaining parameters constant.

The tests were carried out on the surfaces of $5 \times 5 \mathrm{~mm}^{2}$ presented above. Various sampling intervals were used during the measurements: $\Delta \mathrm{X}=$ $\Delta \mathrm{Y}=5,10,20,50,100 \mu \mathrm{m}$.

In order to compare the relative values (parameters tested with a different sampling interval) for the values of the parameters of the tested surface with $\Delta \mathrm{X}=\Delta \mathrm{Y}=5 \mu \mathrm{m}$, the value equal to 1 was adopted, for the remaining $\Delta \mathrm{X}=$ $\Delta Y$ deviations from the value equal to 1 . Thus, you can see the differences between the parameter values caused by the change of the sampling interval (Fig. 2, Table 3).

\section{SURFACE TESTS}

\section{Anisotropic mixed surface}

As a result of surface measurements with varying sampling interval presented above (Fig. 2) values of selected individual roughness parameters were analyzed and compared (see Fig. 3 and Fig. 4).

\section{Anisotropic periodic (turned surface)}

Table 3 below shows parametric values of anisotropic surface measurements, which alter depending on the applied sampling intervals. During the measurements varying sampling intervals were used: $\Delta X=\Delta Y=5,10,20,50,100 \mu \mathrm{m}$. The value equal to 1 was adopted (see column 2 in Table 3) to facilitate the comparison between the relative values (i.e. parameters tested with a different sampling interval). The value of 1 corresponds to the values of the parameters of the tested surface with $\Delta \mathrm{X}=\Delta \mathrm{Y}=5 \mu \mathrm{m}$. Graphic representation of the parameters presented in Table 3 is illustrated further in Figure 5.

Table 3. Change in parameter values obtained during turned surface measurement with different sampling intervals relative to $\Delta \mathrm{X}=\Delta=5 \mu \mathrm{m}$

\begin{tabular}{|c|c|c|c|c|c|}
\hline \multicolumn{6}{|c|}{ Sampling Interval } \\
\hline$\Delta \mathrm{X}=\Delta \mathrm{Y}[\mu \mathrm{m}]$ & 5 & 10 & 20 & 50 & 100 \\
\hline Roughness parameters & \multicolumn{7}{|c|}{$\Delta$} & 1.023 & 0.92 \\
\hline $\mathrm{Sa}$ & 1 & 0.992 & 0.984 & 0.846 & 0.765 \\
\hline $\mathrm{Sz}$ & 1 & 0.944 & 0.915 & 0.888 & 0.792 \\
\hline $\mathrm{St}$ & 1 & 0.959 & 0.95 & 1.025 & 0.954 \\
\hline $\mathrm{Sq}$ & 1 & 1 & 0.993 & 0.892 & 0.739 \\
\hline $\mathrm{Sp}$ & 1 & 0.982 & 0.972 & 0.884 & 0.839 \\
\hline $\mathrm{Sv}$ & 1 & 0.937 & 0.931 & 0.376 & 0.193 \\
\hline $\mathrm{Sdq}$ & 1 & 0.824 & 0.614 & 0.053 & 0.014 \\
\hline $\mathrm{Ssc}$ & 1 & 0.477 & 0.2 & & \\
\hline
\end{tabular}




\section{$\square S a \square S z \square S t \quad \square S q u S p \quad \square S v \quad \square S d q u S s c$}

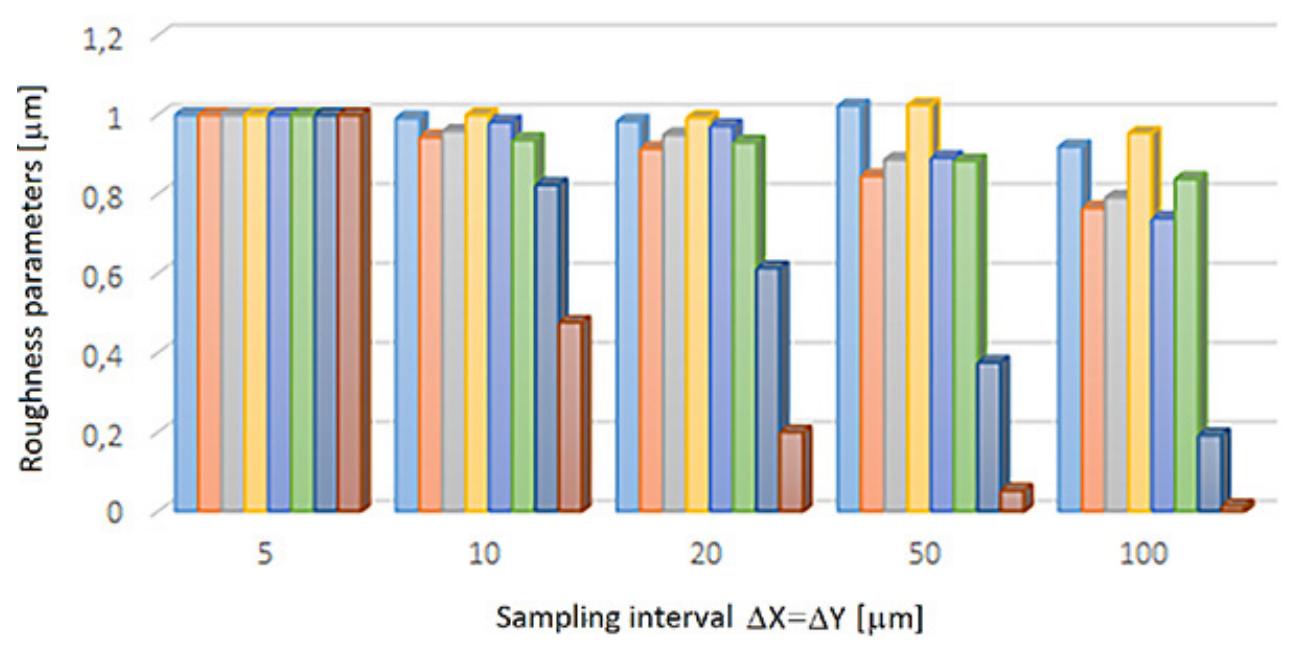

Fig. 5. Change in parameters values obtained during surface measurement with different sampling intervals relative to $\Delta \mathrm{X}=\Delta \mathrm{Y}=5 \mu \mathrm{m}$

\section{Anisotropic random (milled surface)}

Table 4 presented below shows parametric values of anisotropic random surface measurements. The values evidently change depending on the introduced sampling intervals. The manner of data presentation, used parameters, sampling interval as well as the method are analogical to those implemented and shown in Table 3. Parameters presented in Table 4 are presented graphically in Figure 6.

\section{Isotropic random}

Table 5 presents results of isotropic random surface measurements, whose values change depending on the used sampling intervals. As before, the way of presenting data, used parameters, sampling interval, and the method are analogical. Parameters presented in Table 5 are shown graphically in Figure 7.
Studying the changes in the parametric values in the Tables 3, 4, 5, and inspecting the same values illustrated in corresponding Figures 5, 6, 7 , it can easily be noticed that a majority of the 8 parametres change their values along with the change of sampling interval. The values noticeably decrease, with values of two parameters, namely $S S C$ and $S d q$, dropping drastically with the rise in the sampling interval.

\section{ANALYSIS OF SAMPLING INTERVAL SELECTION}

The purpose of the study is to find (calculate) the maximum sampling interval $(\Delta \mathrm{X}=\Delta \mathrm{Y})$ that guarantees coverage of points measured with a certain probability.

Table 4. Change in parameter values obtained during milled surface measurement with different sampling intervals relative to $\Delta \mathrm{X}=\Delta=5 \mu \mathrm{m}$

\begin{tabular}{|c|c|c|c|c|c|}
\hline \multicolumn{6}{|c|}{ Sampling Interval } \\
\hline$\Delta \mathrm{X}=\Delta \mathrm{Y}[\mu \mathrm{m}]$ & 5 & 10 & 20 & 50 & 100 \\
\hline Roughness parameters & \multicolumn{7}{|l|}{} \\
\hline $\mathrm{Sa}$ & 1 & 0.97 & 0.958 & 0.951 & 0.963 \\
\hline $\mathrm{Sz}$ & 1 & 0.863 & 0.847 & 0.835 & 0.871 \\
\hline $\mathrm{St}$ & 1 & 0.854 & 0.834 & 0.83 & 0.885 \\
\hline $\mathrm{Sq}$ & 1 & 0.968 & 0.954 & 0.95 & 0.969 \\
\hline $\mathrm{Sp}$ & 1 & 0.79 & 0.77 & 0.768 & 0.83 \\
\hline $\mathrm{Sv}$ & 1 & 0.915 & 0.9 & 0.884 & 0.938 \\
\hline $\mathrm{Sdq}$ & 1 & 0.951 & 0.894 & 0.7 & 0.283 \\
\hline $\mathrm{Ssc}$ & 1 & 0.745 & 0.576 & 0.292 & 0.052 \\
\hline
\end{tabular}




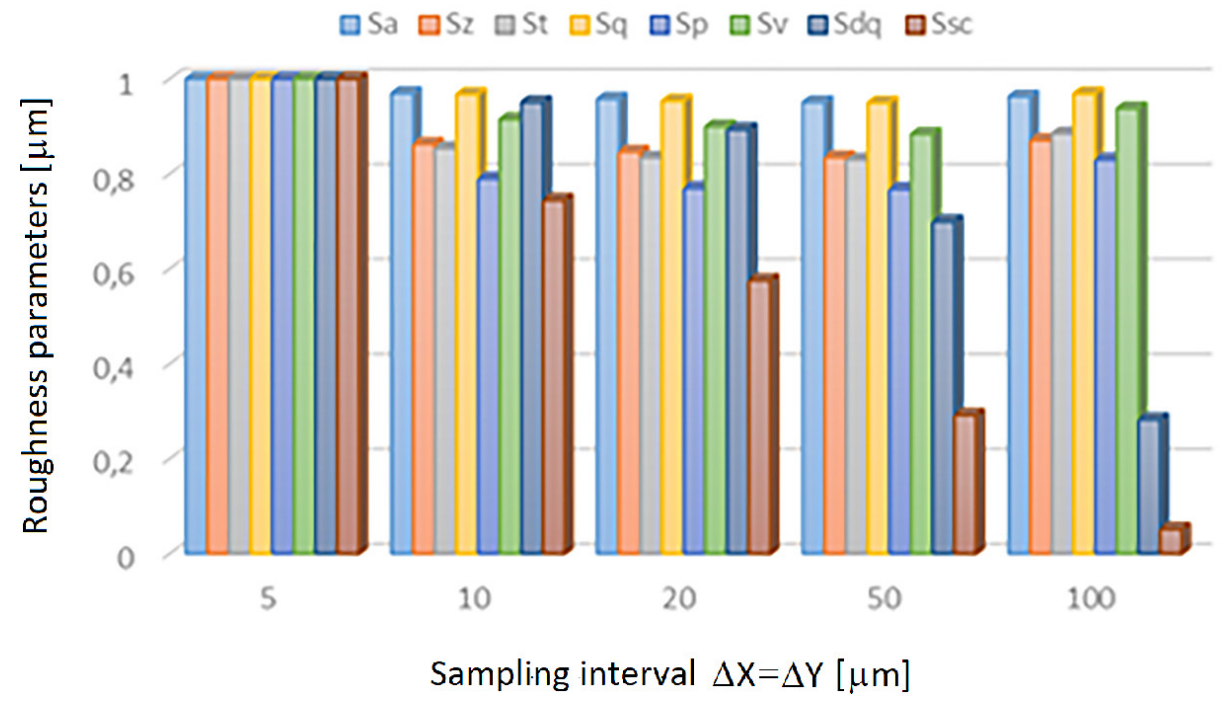

Fig. 6. Change in parameters values obtained during milled surface measurement with different sampling intervals relative to $\Delta \mathrm{X}=\Delta \mathrm{Y}=5 \mu \mathrm{m}$

Table 5. Change in parameter values obtained during isotropic random surface measurement with different sampling intervals relative to $\Delta \mathrm{X}=\Delta=5 \mu \mathrm{m}$

\begin{tabular}{|c|c|c|c|c|c|}
\hline \multicolumn{6}{|c|}{ Sampling Interval } \\
\hline$\Delta \mathrm{X}=\Delta \mathrm{Y}[\mu \mathrm{m}]$ & 5 & 10 & 20 & 50 & 100 \\
\hline Roughness parameters & \multicolumn{5}{|l|}{} \\
\hline $\mathrm{Sa}$ & 1 & 0.997 & 0.994 & 0.994 & 1.002 \\
\hline $\mathrm{Sz}$ & 1 & 0.988 & 0.956 & 0.84 & 0.776 \\
\hline $\mathrm{St}$ & 1 & 0.972 & 0.943 & 0.835 & 0.808 \\
\hline $\mathrm{Sq}$ & 1 & 0.997 & 0.993 & 0.995 & 1.004 \\
\hline $\mathrm{Sp}$ & 1 & 0.96 & 0.898 & 0.803 & 0.764 \\
\hline $\mathrm{Sv}$ & 1 & 0.984 & 0.984 & 0.864 & 0.854 \\
\hline Sdq & 1 & 0.929 & 0.827 & 0.584 & 0.37 \\
\hline Ssc & 1 & 0.657 & 0.442 & 0.17 & 0.059 \\
\hline
\end{tabular}

\section{$\square S a \square S z \quad$ St $\square S q \square S p \square S v a S d q \square S s c$}

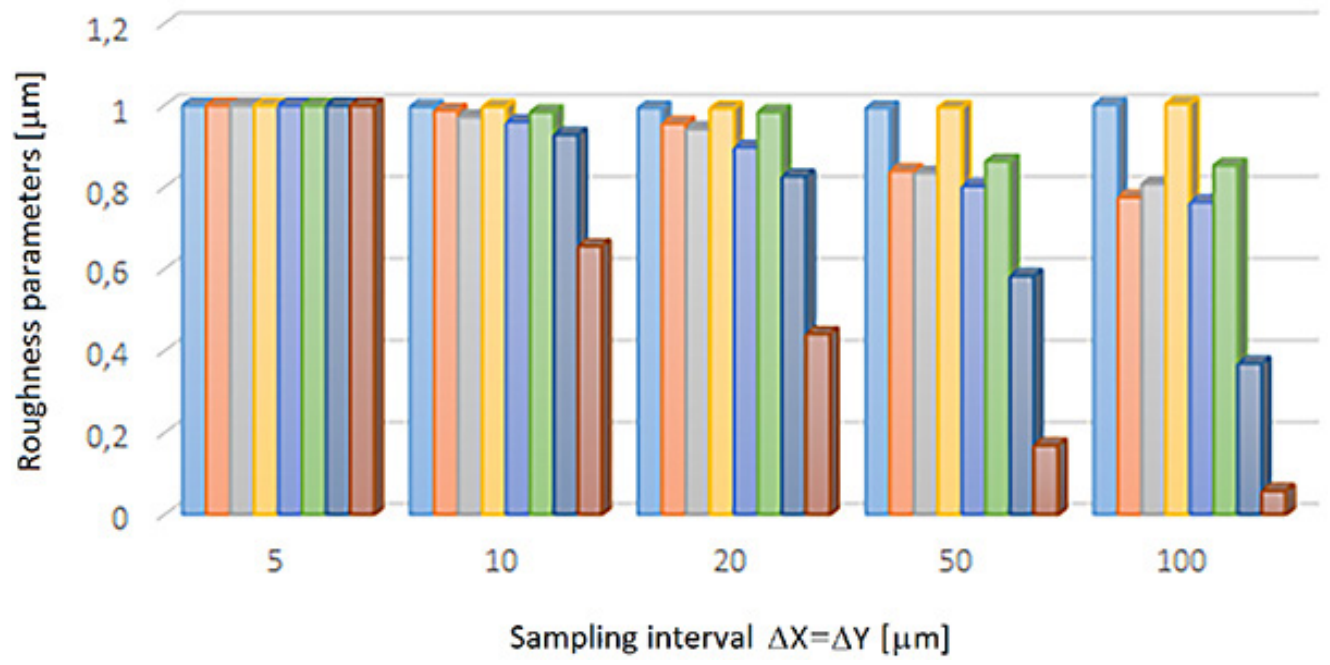

Fig. 7. Change in parameters values obtained during isotropic random surface measurement with different sampling intervals relative to $\Delta \mathrm{X}=\Delta \mathrm{Y}=5 \mu \mathrm{m}$ 
a)

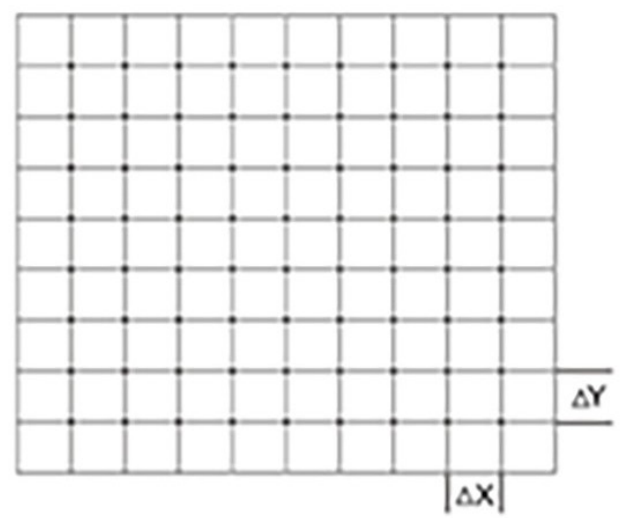

b)

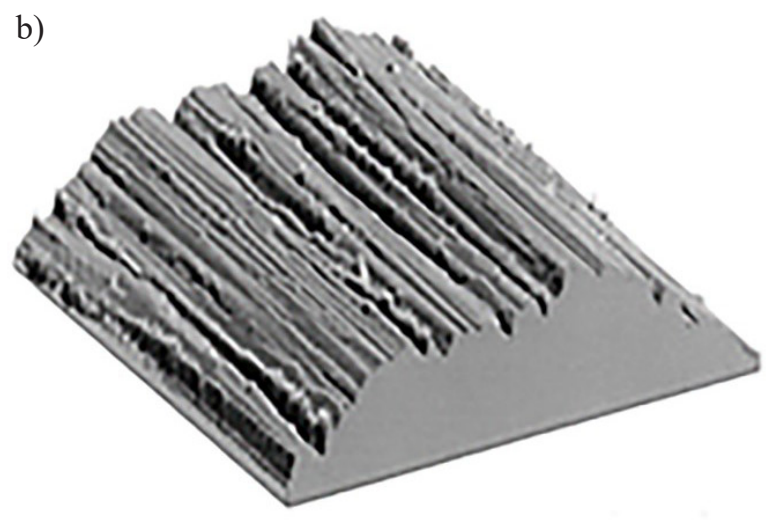

Fig. 8. a) measuring graticule, b) three-dimensional image

The measurement of the geometrical structure of the surface in a $3 \mathrm{D}$ system relies on the measurement of parallel profiles in mutually perpendicular directions using a measuring stylus, which moves on the examined surface measuring it at a given sampling period $\Delta \mathrm{X}=\Delta \mathrm{Y}$. Consequently, one obtains the so-called measuring grid, which corresponds to the measured surface (Fig. 8a).

Points located at the intersection of the grid correspond to the location of the points of measurement. By superimposing a measuring grid onto the surface, a three-dimensional image of the surface is obtained (Fig. 8b). The points (measurement grid nodes) at the intersection of the grid are the measurement locations.
The reliability of the analyzed surfaces and the value of the roughness parameters largely depends on the density of the mesh nodes (proximity of the measurement points). It becomes clear that when $\Delta \mathrm{X}=\Delta \mathrm{Y} \rightarrow 0$, then the measurement results are getting increasingly accurate. In case when $\Delta \mathrm{X}=\Delta \mathrm{Y} \rightarrow \infty$ their fidelity is lost.

In turn, when the sampling interval increases, their accuracy is lost, as shown in Figure 9.

With increasing the sampling interval, the differences between the profiles of the examined surfaces are significant and visible. This is because the instrument ignores individual peaks and dimples between passes.

a)

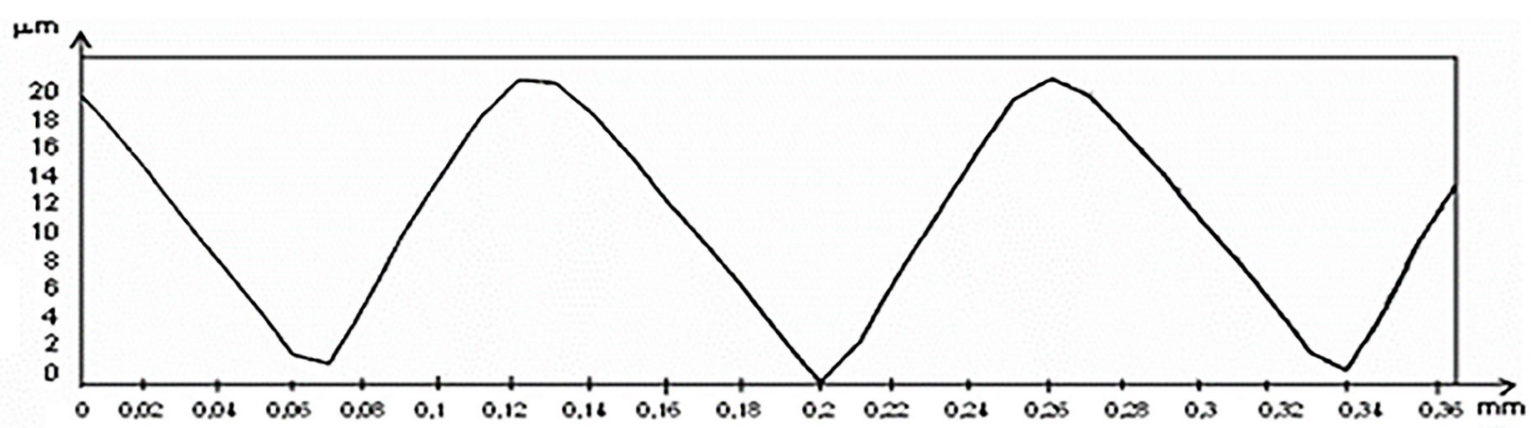

b)

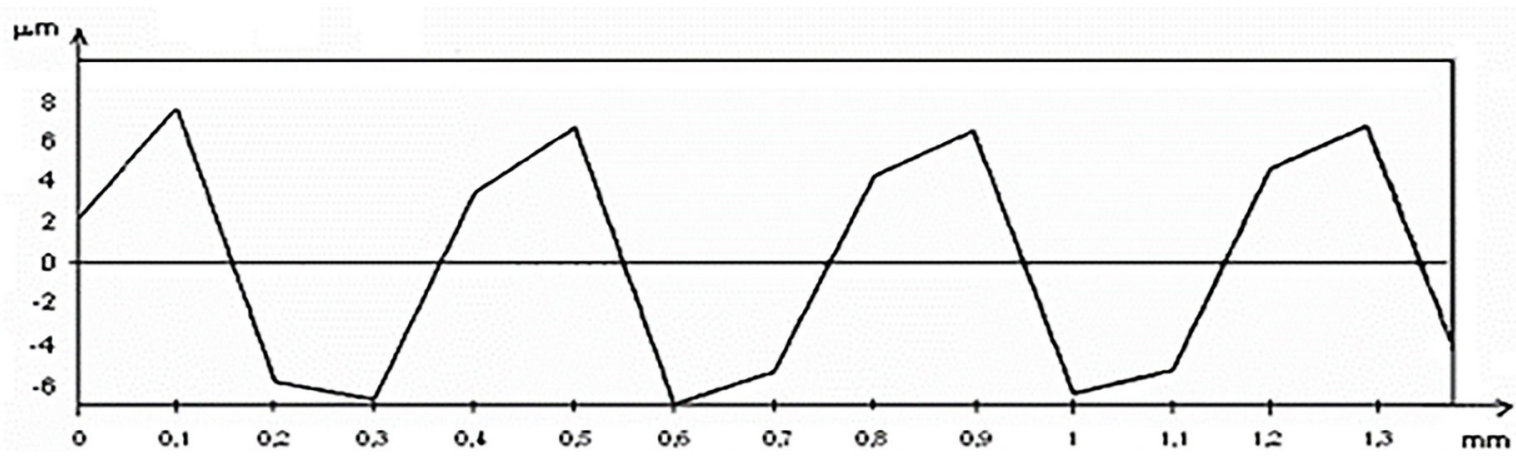

Fig. 9. Surface profile measured with: a) $\Delta \mathrm{X}=\Delta \mathrm{Y}=10 \mu \mathrm{m}$, b) $\Delta \mathrm{X}=\Delta \mathrm{Y}=100 \mu \mathrm{m}$ 

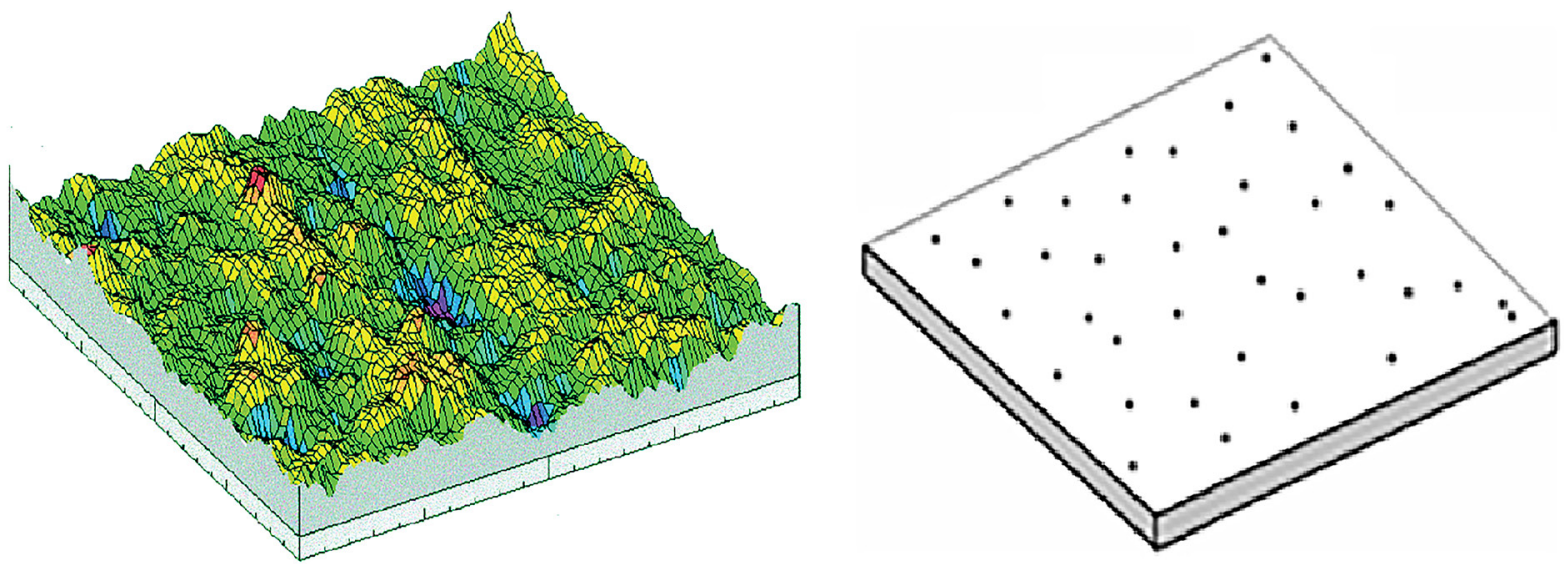

Fig. 10. Diagram showing the assumption of treating extreme surface irregularities as dimensionless points [43]

So what should be the largest $\Delta \mathrm{X}=\Delta \mathrm{Y}$ to fully reproduce the examined surface image and obtain reliable values of roughness parameters, reducing the time and cost of the measurement?

In order to answer the question posed, it was assumed that the extreme surface irregularities (more precisely their vertices and pits) were marked as dimensionless points. In this way, the set of randomly distributed points resulting from the adopted assumptions reflects the irregularities on the tested surface (Fig. 10).

In addition, the following axiomatic assumptions were introduced:

1. The target area is a continuous area.

2. Extreme points form a set of points of equal probability on the surface.

3 . The extreme points of elevations and depressions are equal and possess approximant values.

As a result of measuring the area, the measuring grid overlaps with a disordered set of points as shown in the Figure 11.

The probability of covering all points with the measurement grid $\mathrm{P} \rightarrow 1$ may take place only in the case when $\Delta \mathrm{X}=\Delta \mathrm{Y} \rightarrow 0$. However, this case is not feasible, and the use of a sampling interval that approaches zero is absurd.

In fact, extreme surface irregularities, previously denoted as dimensionless points, can be interpreted as elements with specific dimensions and boundaries. Therefore, a circle with specific dimensions was inscribed in the characteristic inclusions and recesses of the surface. It turns out that almost every surface unevenness (based on calculations of the average curvature of individual vertices) has a similar value of curvature (Fig. 12).

Therefore, the measurement surfaces were treated as a set of chaotically distributed peaks

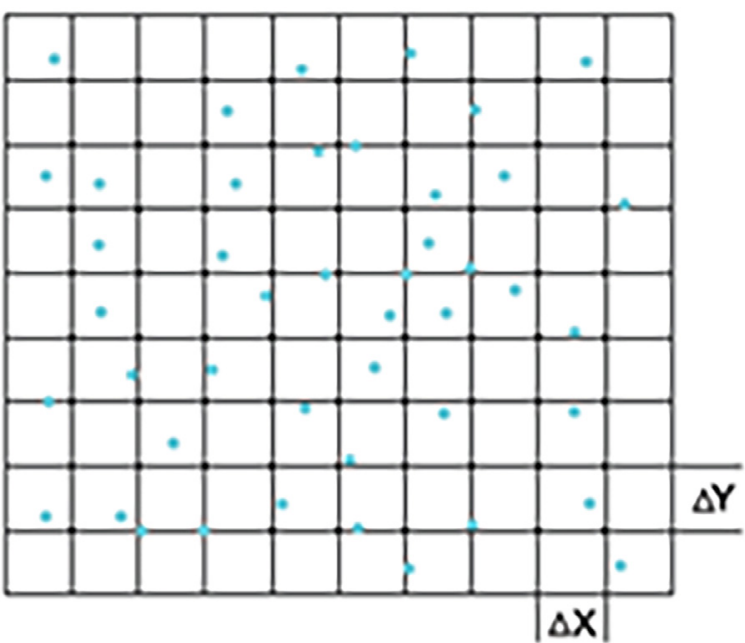

Fig. 11. Covering a disordered set of points with a measurement grid

and pits, forming on the surface a set of elements of equal probability in the shape of cones with rounded vertices.

In order to determine the value of surface unevenness in the form of cones, the following normalized measurement parameters were used: SsC - the arithmetic mean of the curvature of the surface unevenness peaks and $S d q$ - the mean square inclination of the surface unevenness. Based on the parameters mentioned, the radius of rounding the peaks of the inequality was calculated: $\mathrm{Rw}=$ 1/Ssc (seen Fig. 13).

Subsequently, the scheme of covering the tested surface with a measuring grid is slightly different than in Figure 12. The set of cones is an unordered set of elements (Fig. 14., Hatched fields), the ordered set is the measuring grid formed during 3D measurements (when plotting the measuring surface) with the sampling interval, most often $\Delta \mathrm{X}=\Delta \mathrm{Y}$. 


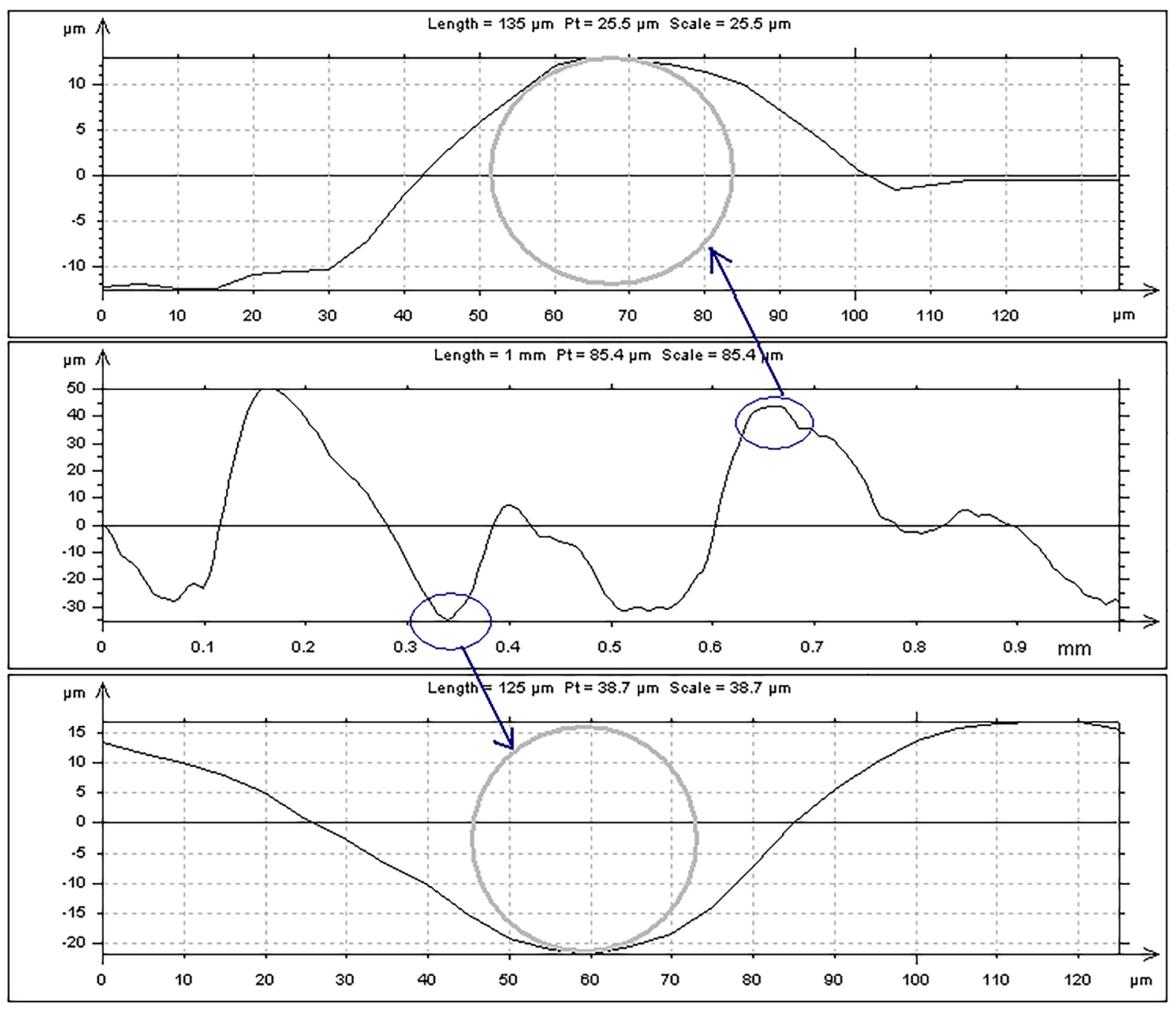

Fig. 12. A circle inscribed in the vertices and recesses of the surface unevenness

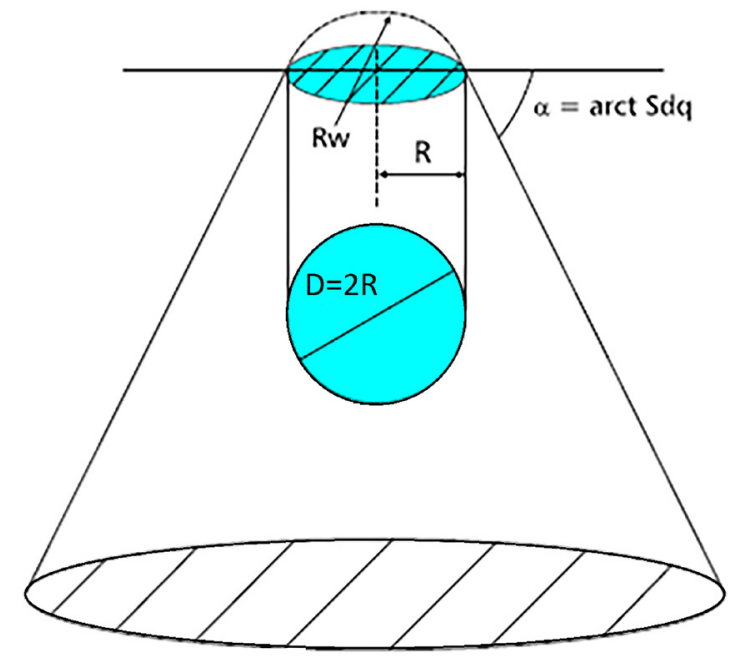

Fig. 13. Graphical interpretation of the measurement surface unevenness element

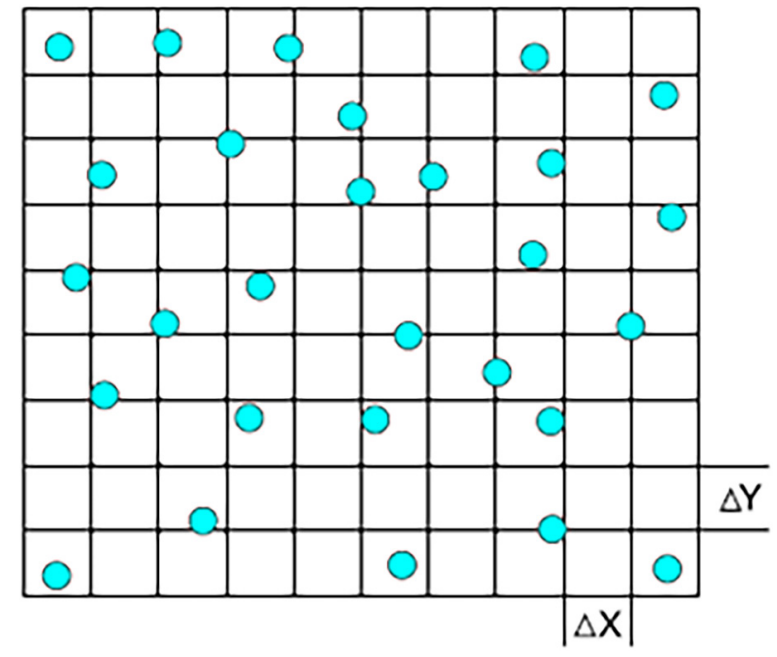

Fig. 14. Scheme of surface coverage with a measuring grid

the part of the cone with rounded vertices. The transition points between the extreme points do not play a decisive role in the parametric evaluation of the SGP. 


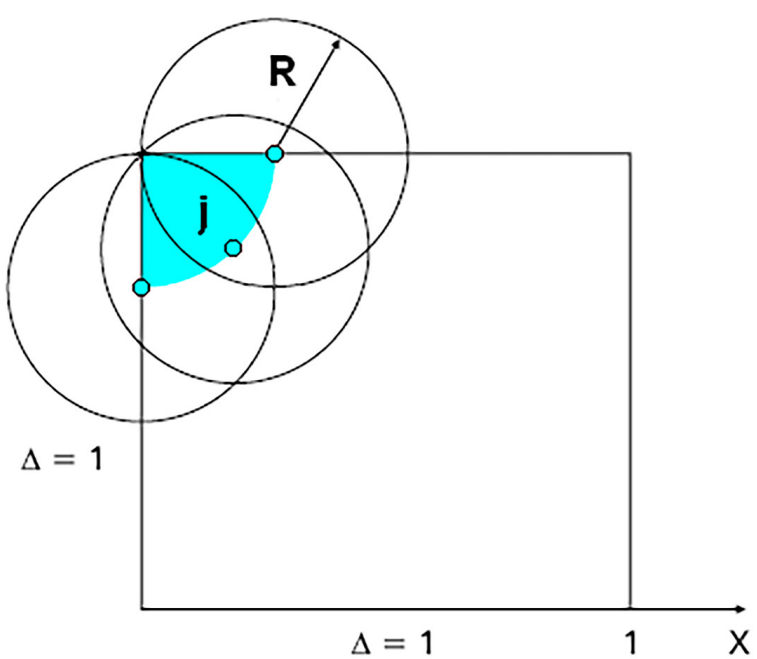

Fig. 15. Scheme of coverage of finite elements with radius $\mathrm{R}$ with nodes of the measuring grid

Thus, the task formally comes down to the analysis of the coverage of a disordered (chaotic) set " $\mathrm{A}$ " with the set " $\mathrm{B}$ " arranged in the shape of a square grid $\Delta \mathrm{X}=\Delta \mathrm{Y}$. The basic task of the analysis of the mutual overlapping of such sets is to determine the necessary and sufficient value of the measuring segment $\Delta$ of set "B", guaranteeing the given probability $\mathrm{P}$ (j) of covering the points of set A with points of set B.

A measurement grid is an ordered set of points obtained as a result of isometric and symmetrical transformations with respect to the axis of symmetry. Therefore, considerations were made on the basis of one elementary link of the grid. We take $\Delta=1$.

Presented in Figure 15. the hatched field marked with the symbol " $\mathrm{j}$ " is the place where the appearance of the centers of the circles with radius $\mathrm{R}$ guarantees that the measurement grid node will hit the surface irregularities in the shape of cones with rounded vertices. These inequalities are shown in Figure 16 in the form of circles with radius $\mathrm{R}$.

A circle with radius $R$ will cover one of the nodes of the square if the distance between the center of the circle and the node is less than or equal to the radius $R$. The value of " $\mathrm{j}$ " depends on the dimension ratio $\mathrm{R}$ - the radius of the apex circumference and the sampling interval $\Delta$, hence $\mathrm{j}=\mathrm{R} / \Delta$.

The hatched zones represent the areas where the center of a circle with radius " $\mathrm{j}$ " guarantees coverage of at least one of the mesh nodes. Nonhatched areas stand for the so-called dead zone, which, depending on the case under consideration, has the following shape:

- for $\mathrm{j} \leq 1 / 2$, corresponding to the curvilinear rhombus (a), the shaded area is $\pi \mathrm{j}^{2}$ of the square $\Delta=1$,

- for $j \leq 1 / 2 \leq \sqrt{2} / 2$, corresponding to the curvilinear rhombus (b), the probability P (j) equals the area of the square $\Delta=1$ minus the areas of the curvilinear rhombus in its center,

- for $j \geq \sqrt{ } 2 / 2$, corresponding to midpoint (c), the location of the center of the circle at any point in the square guarantees coverage of at least one of the nodes $P(j)=1$.

In order to find the probability $P(j)$ for case b), it is necessary to calculate the area of the non-hatched curvilinear rhombus forming the dead zone. After deriving the formula, it was obtained. a)

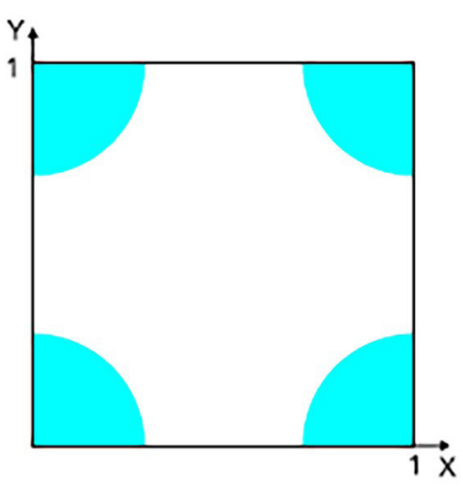

b)

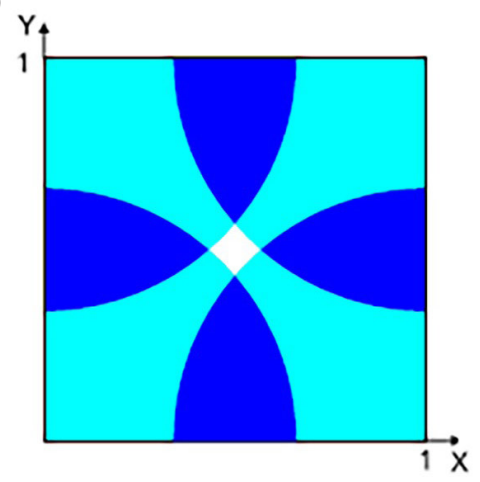

c)

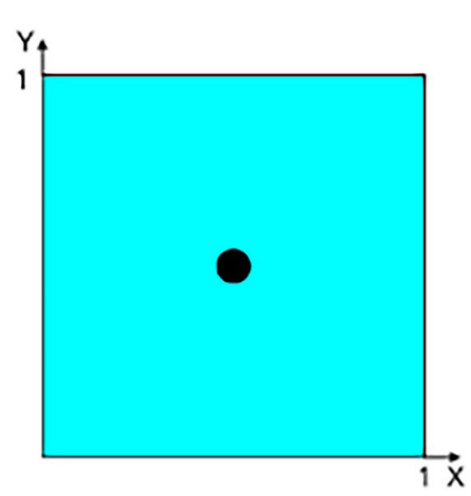

Fig. 16. Scheme of possible positions of the fields (zones) of the center of the element with the radius " $j$ "; a) $j \leq 1 / 2$; b) $1 / 2 \leq j \leq \sqrt{2} / 2$; c) $j \geq \sqrt{ } 2 / 2$ 


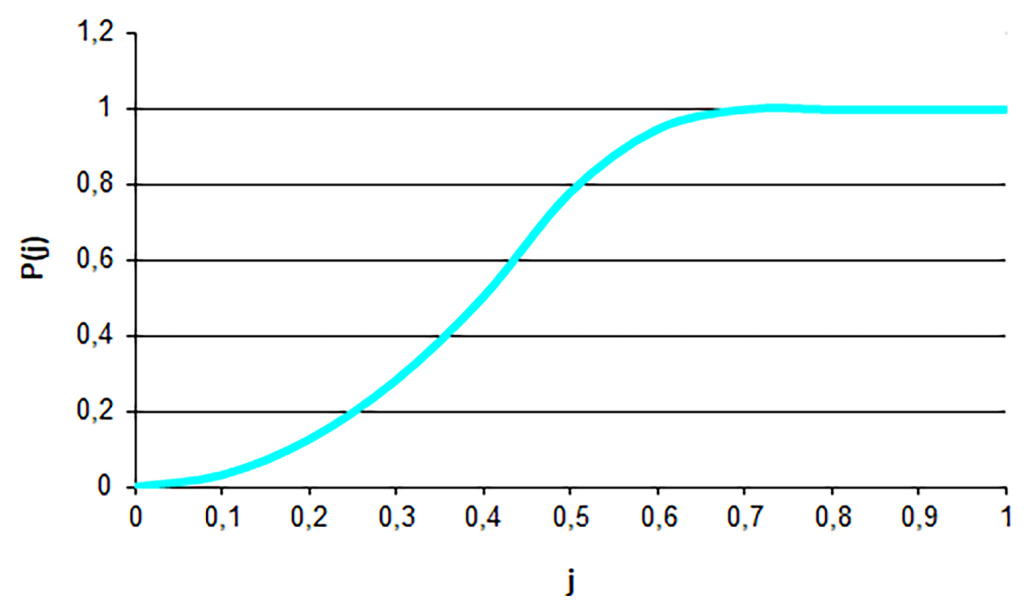

Fig. 17. Graphical interpretation of the probability of covering the surface of a set of elements with dimensions $\mathrm{R}$ with a grid of measurement points with dimensions $\Delta$

$P(j)=\left\{1-4\left\{\frac{1}{2}\left[0.5-\sqrt{j^{2}-0.5^{2}}+j^{2}\left(\arcsin \frac{\sqrt{j^{2}-0.5^{2}}}{j}-\arcsin \frac{0.5}{j}\right)\right]\right\}=\left\{\begin{array}{c}j \leq \frac{1}{2} \\ 1\end{array}\right.\right.$

A graphic interpretation of the formula is provided in Figure 17. The formula (1) and the graph (Fig. 17) were prepared for the case where the measurement grid nodes were theoretical

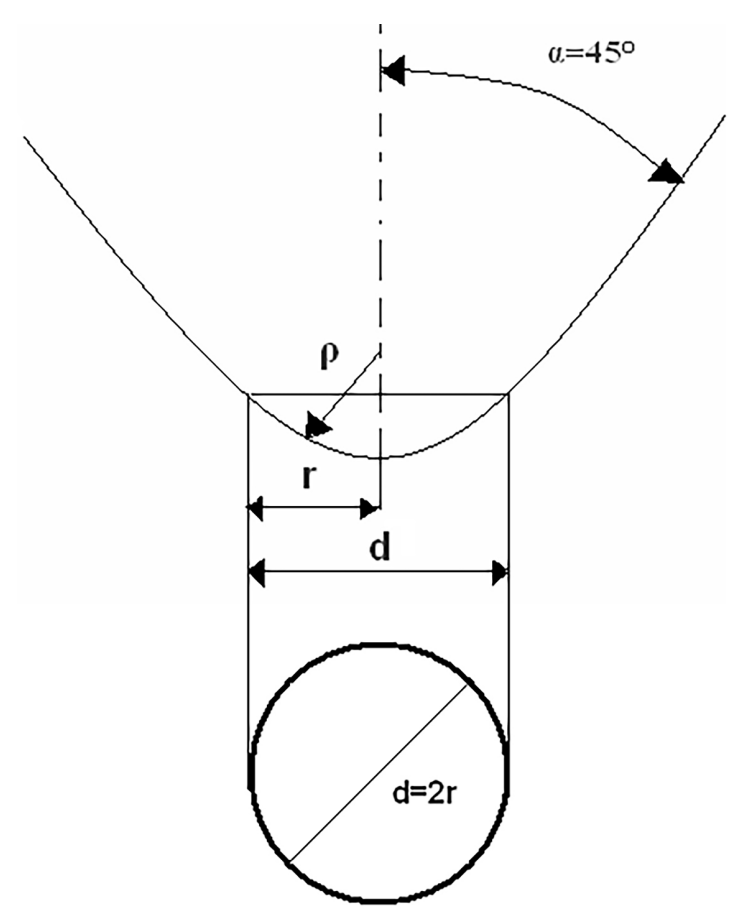

Fig. 18. Graphical interpretation of the contact element of the measuring stylus with the surface dimensionless points. In fact, the points (i.e. points of measurement) occurring at the intersection of the grid (see Fig. 18) are not dimensionless points but elements with specific dimensions. Their dimensions are related to the value of the rounding radius of the measuring stylus $\rho$.

As a result, the scheme of covering the surface roughness with the measuring grid takes the form presented in Figure 19.

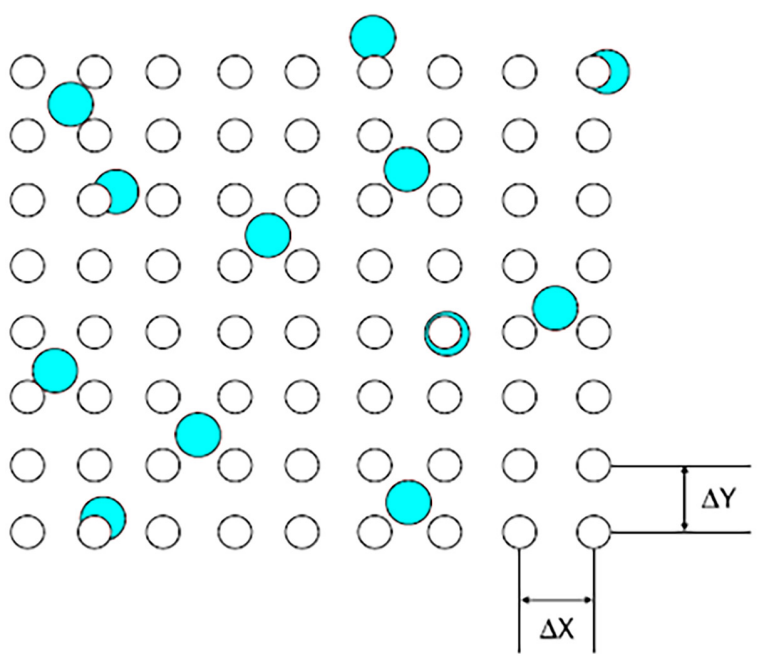

Fig. 19. Scheme of coverage of a disordered random (chaotic) set with an ordered set in the shape of a square grid $\Delta \mathrm{X}=\Delta \mathrm{Y}$ 


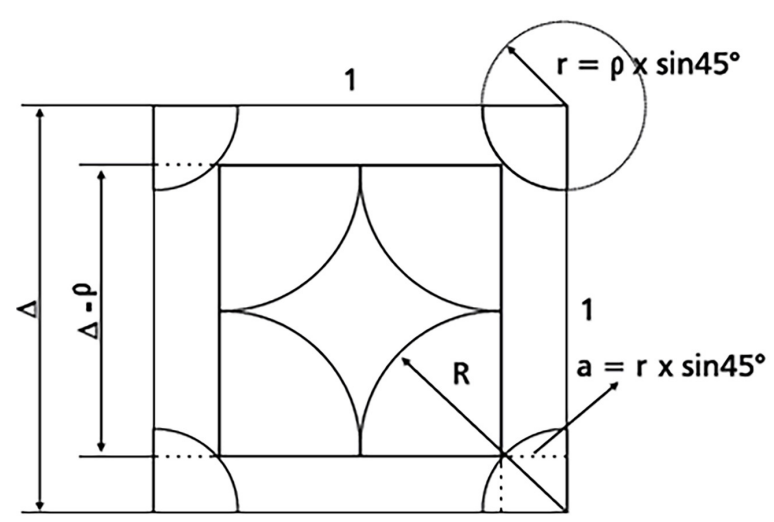

Fig. 20. The actual scheme of covering the test surface with a sampling grid

In this case, the task comes down to superimposing the set of mesh nodes elements on the set of elements related to the surface roughness values. The actual scheme of covering the tested surface with a measuring grid was considered as follows (Fig. 20).

Figure 20 illustrates the following relationship:

$$
\frac{R}{\Delta-\rho} \leq \frac{\sqrt{2}}{2}
$$

as a result of which

$$
R=0.7 \Delta-0.7 \rho
$$

Taking into account the radius of rounding of the measuring stylus $\rho$, the final formula (4) was obtained, allowing to calculate the maximum sampling length $\Delta \mathrm{X}=\Delta \mathrm{Y}$ guaranteeing $100 \%$ full coverage of the peaks of the tested unevenness with the measuring grid.

$$
\Delta_{p=1}=1.41 \times R+\rho
$$

where: $R$ - the radius of the circumference of the vertex representing the circular element of the vertex set, $\rho$ - rounding radius of the measuring needle.

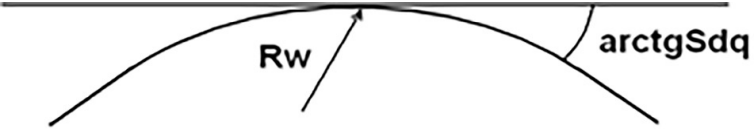

Fig. 21. Graphic interpretation of the $S d q$ parameter

The value of the radius $R$ is the product of the rounding radius of the vertex of the inequality $\mathrm{Rw}$ and the sine of the angle $\alpha$.

$$
R=R w \times \sin \alpha
$$

In order to calculate $R w$, the normalized parameters $S s c$ and $S d q$ were used. $R w$ has the reciprocal value of the arithmetic mean curvature of the peaks of surface unevenness,

$$
R w=1 / S s c
$$

while the angle $\alpha$ is closely related to the $S d q$ parameter - the mean square slope of surface unevenness (Fig. 21).

$$
\begin{gathered}
S d q=\operatorname{tg} \alpha \\
\alpha=\operatorname{arctg} S d q
\end{gathered}
$$

According to the derived formula (4), the maximum sampling length $\Delta \mathrm{X}=\Delta \mathrm{Y}$ was calculated, which guarantees full $100 \%$ coverage of the peaks of the tested unevenness with the measuring grid.

\section{RESEARCH WITH THE USE OF A FORMULA (2)}

Sixty surfaces with different geometrical shapes and different height parameters from $\mathrm{St}$ (height of unevenness) $=0.426 \mu \mathrm{m}$ to $\mathrm{St}=141$ $\mu \mathrm{m}$ were examined.

The following parameters were measured in all surfaces: $S d q, S s c$.

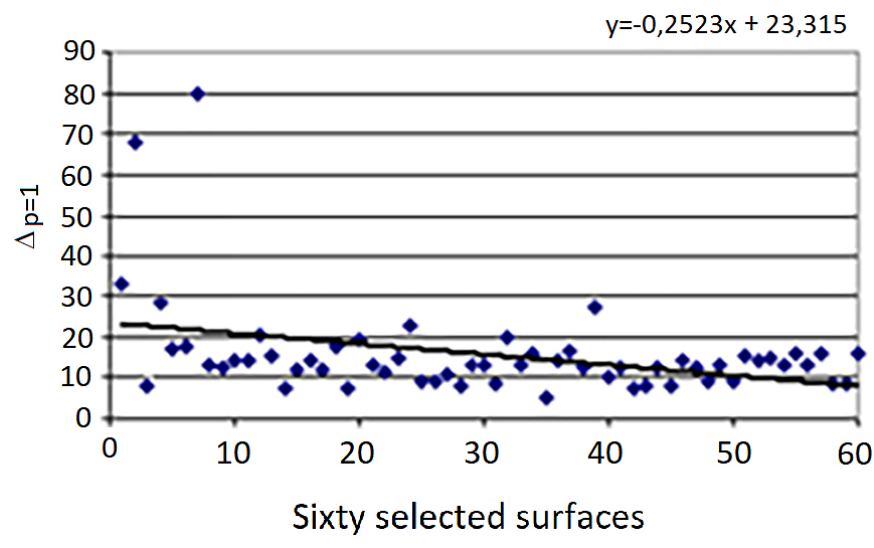

Fig. 22. The sampling length $\Delta_{\mathrm{p}=1}$ guarantees $100 \%$ coverage of the peaks of the roughness 
a)

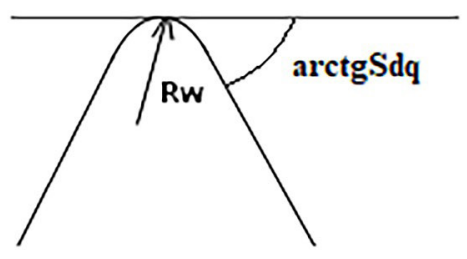

b)

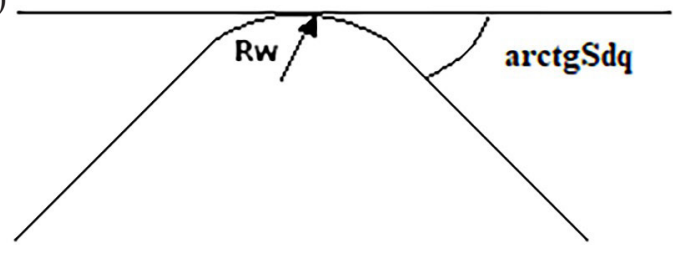

Fig. 23. Cone-shaped elevation, a) large values of Sdq and Ssc parameters, b) high value of the Sdq parameter and small value of Ssc

Then, the maximum sampling length $\Delta \mathrm{X}=\Delta \mathrm{Y}$, which guarantees full $100 \%$ coverage of the peaks of the tested inequalities with the measuring grid, was calculated according to the formula (4). The calculation results are presented in Figure 22.

For surfaces with a high inclination of the roughness (high value of the $S d q$ parameter) and high curvature of the vertices (high value of the SSC parameter), the maximum sampling length $\Delta \mathrm{p}=1$ guaranteeing full $100 \%$ coverage of the peaks of the tested inequalities with the measuring grid has a small value of $7 \pm 8 \mu \mathrm{m}$. This is due to the characteristic shape of the tested unevenness (narrow steep hills with a large rounded apex) (see Fig. 23a).

A too large sampling length could result in omission of vertices, and, consequently, measuring the area would be inaccurate. Therefore, in order to carry out precise tests, the smallest possible value of $\Delta \mathrm{X}=\Delta \mathrm{Y}$ should be used.

For surfaces characterized by a high inclination of the roughness (high value of the $S d q$ parameter) and a small curvature of the vertices (low value of the SSC parameter), the maximum sampling length $\Delta_{\mathrm{p}=1}$ guaranteeing a full $100 \%$ coverage of the peaks of the tested inequalities with the measuring grid has a value of approx. $13 \mu \mathrm{m}$. This is due to the wide shape of the irregularities (gentle elevations with a small radius of rounding at the tops) (see Fig. 23b). In this case, the measuring instrument identifies irregularities of the shape under consideration much more easily. Therefore, in order to carry out accurate tests, the sampling interval $\Delta \mathrm{X}=\Delta \mathrm{Y}$ with values in the order of $12 \pm 13 \mu \mathrm{m}$ can be used, thus reducing the time and cost of the tests.

\section{CONCLUSIONS}

Based on the tests performed, it can be concluded that the sampling interval has a significant impact on the parametric evaluation of the SGP. Accuracy of measurements decreases with increasing sampling interval. When creating a large sampling interval, e.g. $\Delta \mathrm{X}=\Delta \mathrm{Y}[\mu \mathrm{m}]$, one should take into account that the obtained measurement results will be not very accurate. It may happen that they do not give a real image of the tested surface, because the moving stylus will ignore the detail in the curvature of the tested surface. The hybrid parameters: $S S C$ - arithmetic mean curvature of the vertices of surface unevenness and $S d q$ - mean square slope of surface irregularities, are very sensitive to the sampling interval. The sampling interval should be selected depending on the type of the tested surface. It largely depends on the shape of its geometric structure. For surfaces with a high inclination of unevenness and high curvature of the peaks, the smallest possible sampling interval of $7 \pm 8 \mu \mathrm{m}$ should be used. For surfaces characterized by a high inclination of unevenness and a small curvature of the peaks, a larger sampling interval $\Delta \mathrm{X}=\Delta \mathrm{Y}$ of $12 \pm 13 \mu \mathrm{m}$ can be used, thus reducing the time and cost of testing.

\section{REFERENCES}

1. Chang H.C., Lin A.C. An innovative algorithm for statistic sampling of measured points and simplifying measuring probe orientation for sculpture surfaces. International Journal of Advanced Manufacturing Technology. 2009; 41(7-8): 780-798. DOI: 10.1007/s00170-008-1513-6.

2. Yang Ch., Chaoyang Peng Ch., Chen Y, Luo T., Chu J. Space-filling scan paths and Gaussian processaided adaptive sampling for efficient surface measurements. Precision Engineering. 2018;54:412419. DOI: 10.1016/j.precisioneng.2018.07.011.

3. Chryssolouris G., Fassois S., Vasileiou E. Data sampling technique (DST) for measuring surface waving. International Journal of Production Research. 2002; 40(1): 165-177. DOI: 10.1080/00207540110072993.

4. Hallerman G.R., Shirley L.G. A comparison of surface contour measurements based on speckle pattern sampling and coordinate measuring machines. Harding, K.G., Svetkoff, D.J. Three-Dimensional Imaging and Laser-Based Systems for Metrol- 
ogy and Inspection II. 1997; 2909: 89-97. DOI: $10.1117 / 12.263314$

5. Hu J., Li Y., Wang Y.H., Cai J.G. Adaptive sampling method for laser measuring free-form surface. International Journal of Advanced Manufacturing Technology. 2004; 24(11-12): 886-890. DOI: $10.1007 / \mathrm{s} 00170-003-1802-\mathrm{z}$.

6. Zahmati J., Amirabadi H., Mehrad V. A hybrid measurement sampling method for accurate inspection of geometric errors on freeform surfaces. Measurement. 2018; 122: 155-167. DOI: 10.1016/j.measurement.2018.03.013.

7. Liubimov V., Oczoś K.E. Wybór racjonalnych parametrów do oceny struktury powierzchni obrobionej elektroerozyjnie. Styp-Rekowski, M., Zagadnienia konstrukcyjne i technologiczne niekonwencjonalnych technik wytwarzania. Wydawnictwo Akademii Techniczno-Rolniczej w Bydgoszczy, 2006; 9: 91-96.

8. Malinsky P., Hnatowicz V., Macková A. Nuclear Instruments and Methods in Physics Research B. Nuclear Instruments and Methods in Physics Research B. 2016; 371: 101-105. DOI: 10.1016/j. nimb.2015.10.001.

9. Meng K., Wan Y.J., Wu F., Shen L.J., Song W.H. A Sampling Method to Measure Surface Roughness of Circular Flat. Zhang, Y., Gao, W. 7-Th International Symposium on Advanced Optical Manufacturing and Testing Technologies: Optical Test and Measurement Technology and Equipment. Proceedings of SPIE, 2014; 9282. DOI: 10.1117/12.2073329.

10. Pagani L., Jiang X., Scott P.J. Investigation on the effect of sampling on areal texture parameters. Measurement. 2018; 128: 306-313. DOI: 10.1016/j. measurement.2018.06.052.

11. Pagani L., Scott P.J. Curvature based sampling of curves and surfaces. Computer Aided Geometric Design. 2018; 59: 32-48. DOI: 10.1016/j. cagd.2017.11.004.

12. Pawlus P. Topografia powierzchni. Pomiar, analiza, oddziaływanie. Oficyna Wydawnicza Politechniki Rzeszowskiej, Rzeszów. 2015.

13. Ren M.J., Cheung C.F., Kong L.B. A bidirectional curve network based sampling method for enhancing the performance in measuring ultra-precision freeform surfaces. Precision Engineering-Journal of the International Societies for Precision Engineering and Nanotechnology. 2013; 37(2): 345352. DOI: 10.1016/j.precisioneng.2012.10.003.

14. Sun L.J., Ren M.J., Yin Y.H. Gaussian Process Based Intelligent Sampling for Measuring Nanostructure Surfaces. Zhang, Y., Wu, F., Xu, M., To, S. 8-Th International Symposium on Advanced Optical Manufacturing and Testing Technology: Optical Test, Measurement Technology, and Equipment, 2016; 9684. DOI: 10.1117/12.2241769.
15. Yin Y., Jun Ren M., Sun L. Dependant Gaussian processes regression for intelligent sampling of freeform and structured surfaces. CIRP Annals. 2017; 66(1): 511-514. DOI: 10.1016/j.cirp.2017.04.063.

16. Zaleski K., Matuszak J., Zaleski R. Metrologia warstwy wierzchniej. Wydawnictwo Politechniki Lubelskiej. Lublin; 2018.

17. www.kla-tencor.com.: Kla-Tencor Corporation Metrology Group: Roughness Measurements With A Stylu Profiler. USA 5/95 M-DS-AN4.

18. Bayerer J., Krahe D. An objective method to quantify the balance of grooves of honed cylinder bores. Trans. 7th Int. Conf. on Metrology and Properties of Engineering Surfaces. Gothenburg, Sweden 1997, 396-403.

19. Nowicki B. Struktura geometryczna. Chropowatość i falistość powierzchni. WNT, Warszawa 1991.

20. Sherrington I., Smith E.H. Areal Fourier analysis of surface topography. Surface Topography; 1990.

21. Chetwynd D.G. The digitisation of surfce profiles. Wear. 1979; 57: 137-145.

22. Guerrero J.L., Black J.T. Stylus tracer resolution and surface damage as determined by scanning electron microscopy, Transaction of the ASME, Journal Engineering for Industry. 1972; 94: 1087-1093.

23. Boryczko A. Conditions for measurement, analogto digital conversion and frequency analysis of irregularities of surface profile. Metrology and Measurement Systems. 2002; 9(2): 159-169.

24. Konczakowski A. Metrologiczne uwarunkowania analizy widmowej struktury geometrycznej powierzchni w diagnostyce obrabiarek. Zeszyty Naukowe Politechniki Gdańskiej, Mechanika. Gdańsk. 1991; 62.

25. Thomas T.R. Rough Surfaces, Secondo Edition, Imperial College Press; 1999.

26. Lin T.Y., Blunt L., Stout K.J. Determination of the proper frequency bandwidth for 3-D topography measurement using spectral analysis. Part I: Isotropic Surface. 1993; 166: 221-232.

27. Stout K.J., Sullivan P.J., Dong W.P., Mainsah E., Luo N., Mathia T., Zahouani H. The Development of Methods for the Characterisation of Roughness in Three Dimensions, Publication EUR 15178 EN Commission of the European Communities; 1993.

28. Nowicki B. Struktura geometryczna. Chropowatość i falistość powierzchni. WNT, Warszawa; 1991.

29. Tsukada T., Sasajima S. An optimum sampling interval for digitizing surface asperity profiles, Wear. 1982; 83: 119-128.

30. PN-85/M-04254: Struktura geometryczna powierzchni. Porównawcze wzorce chropowatości powierzchni obrabianych.

31. Pawlus P., Chetwynd D.G. Efficient characterization of surface topography in cylinder bores, Precision Engineering. 1996; 19: 164-174. 
32. Michalski J. An evaluation of cylinder surface roughness after plateau honing, Advances In Technology of Machines and Mechanical Equipment. 1999; 23(2): 29-69.

33. Dong W.P., Mainsah E., Stout K.J. Determination of appropriate sampling conditions for three-dimensional microtopography measurement, International Journal of Machine Tools and Manufacture. 1996; 36(12): 1347-1362.

34. Poon C.Y., Bhushan B. Numerical contact and station analyses of Gaussian isotropic surface for magnetic head slider/disk contact. Wear. 1996; 202: 68-82.

35. Whitehouse D.J,. Archard J.F. The properties of random surface of significance in their contact, Proceeding Royal Society London. 1970; A316: 97-121.

36. Cholewa W., Korbicz J., Moczulski W., Timofiejczuk A. Metody analizy sygnałów. Korbicz J., Kościelny J.M., Kowalczuk Z., Cholewa W. (red.): Diagnostyka procesów. Modele. Metody sztucznej inteligencji. Zastosowania, WNT, Warszawa. 2002; 115-146.

37. Poon C.Y., Bhushan B. Comparison of surface measurement by stylus profiler, AFM and non-contact optical profiler. Wear. 1995;190:76-88.
38. Greenwood J.A. A unified theory of surface roughness, Proceding Royal Society London; 1984; A(393): 133-157.

39. Tomasik J., Rudziński R. Wpływ odstępu próbkowania na wartości wybranych parametrów chropowatości powierzchni. Pomiary Automatyka Robotyka. 1998; 11.

40. Swornowski P. Wpływ mechanicznego filtrowania końcówki pomiarowej na falistość i chropowatość powierzchni. Archiwum Technologii Maszyn i Automatyzacji. Poznań. 2006; 26(2).

41. PN-EN ISO 3274: 1997 Specyfikacje geometrii wyrobów. Struktura geometryczna powierzchni: metoda profilowa. Charakterystyki nominalne przyrządów stykowych.

42. Michalski J. Dobór odległości profili powierzchni zdeterminowanej. Zeszyty Naukowe Politechniki Rzeszowskiej Mechanika z.66 Wytwarzanie elementów maszyn ze stopów metali o specjalnych właściwościach, Rzeszów; 2006.

43. Oczoś K., Liubimov V. Struktura Geometryczna Powierzchni. Podstawy klasyfikacji z atlasem charakterystycznych powierzchni kształtowych, Rzeszów; 2003. 